\title{
Rutaceae endémicas del Perú
}

\section{Blanca León ${ }^{1,2}$}

${ }^{1}$ Museo de Historia Natural, Av. Arenales 1256, Aptdo. 14-0434, Lima 14, Perú

2 Plant Resources Center, University of Texas at Austin, Austin TX 78712 EE.UU.

blanca.leon@mail.utexas.edu

\section{Resumen}

La familia Rutaceae es reconocida en el Perú por presentar 25 géneros y 76 especies (Brako \& Zarucchi, 1993; Ulloa Ulloa et al., 2004), principalmente árboles y arbustos. En este trabajo reconocemos seis endemismos, representando igual número de géneros. Los taxones endémicos se encuentran en las regiones Bosques Húmedos Amazónicos, Bosques Muy Húmedos Premontanos y Mesoandina, entre los 130 y 2000 m de altitud. Tres taxones se encuentran representados dentro del Sistema Nacional de Áreas Naturales Protegidas por el Estado.

Palabras claves: Rutaceae, Perú, endemismo, plantas endémicas.

\section{Abstract}

The Rutaceae are represented in Peru by 25 genera and 76 species (Brako \& Zarucchi, 1993; Ulloa Ulloa et al., 2004), mainly trees and shrubs. Here we recognize six endemic taxa in the same number of genera. These endemics are found in Humid Lowland Amazonian Forests, Very Humid Premontane Forests and Mesoandean regions, between 130 and 2000 m elevation. Three endemic taxa have been recorded within Peru's protected areas system.

Keywords: Rutaceae, Peru, endemism, endemic plants.

\section{Amyris sandemanii Sandwith}

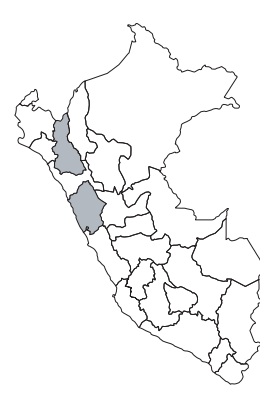
$\mathrm{m}$.

\section{EN, B1ab(iii)}

Publicación: Icon. Pl. 35, t. 3496. 1950. Colección tipo: C. Sandeman

Herbarios: K.

Nombre común: Desconocido.

Registro departamental: AN, CA.

Regiones Ecológicas: MA; 1750—2840

SINANPE: Sin registro.

Herbarios peruanos: HAO (4), HUT (1), USM (2).

Observaciones: Especie arbustiva conocida de unas pocas localidades, en la vertiente del Pacífico. Fue descrita de una planta recolectada en ambientes ecotonales de matorral y bosque en la cuenca alta del Reque. Las poblaciones conocidas se hallan en ambientes propensos a la tala y quema, a lo que se suma la falta de protección formal al hábitat que ocupan.

\section{Esenbeckia cornuta Engl.}

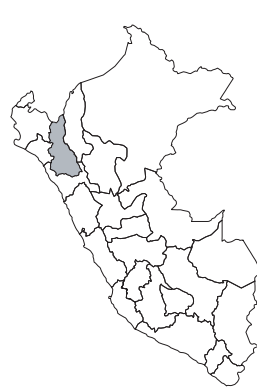

DD

Publicación: Fl. Bras. 12(2): 146. 1874. Colección tipo: A. Warscewicz s.n. Herbarios: K, NY.

Nombre común: Desconocido. Registro departamental: CA.

Regiones Ecológicas: Sin datos; altitud desconocida.

SINANPE: Sin registro.

Herbarios peruanos: Ninguno.

Observaciones: Árbol o arbusto conocido aparentemente sólo de la colección tipo, una planta recolectada en el siglo XIX, en la cuenca del Marañón. Se desconoce el estado actual de sus poblaciones.

\section{Pilocarpus manuensis Skorupa}

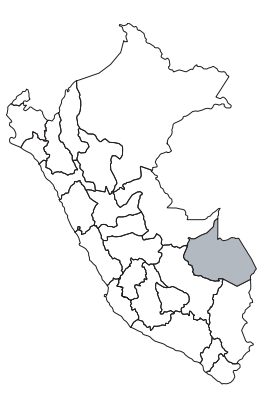
EN, B1a

Publicación: Novon 9(2): 257, f. 1 A-C. 1999.

Colección tipo: R.B. Foster \& H. Beltrán 13183

Herbarios: F, MO, NY.

Nombre común: Desconocido.

Registro departamental: MD.

Regiones Ecológicas: BHA; $350 \mathrm{~m}$.

SINANPE: PNM

Herbarios peruanos: Ninguno.

Observaciones: Esta especie arbórea se conoce del material tipo, recolectado en el Parque Nacional Manu, en 1989, en bosques no inundables. Al parecer, no ha vuelto a ser recolectada desde entonces.

\section{Ravenia biramosa Ducke var. peruviana J.F. Macbr.}

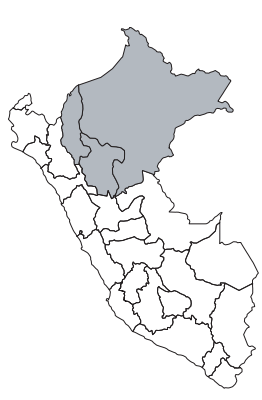

\section{EN, B1a}

Publicación: Field Mus. Nat. Hist., Bot. Ser. 13(3/2): 687. 1949.

Colección tipo: G. Klug 3047

Herbarios: F.

Nombre común: Desconocido.

Registro departamental: AM, LO, SM.

Regiones Ecológicas: BMHP; 180—1100 $\mathrm{m}$.

SINANPE: ZRSC

Herbarios peruanos: HAO (1).

Observaciones: Arbusto conocido de unas pocas localidades en el occidente de la Amazonía peruana, en las cuencas del Huallaga, Mayo y Santiago. Aparentemente, representada en la flora de la Zona Reservada Santiago-Comaina. 


\section{Spathelia terminaloides A.H. Gentry}

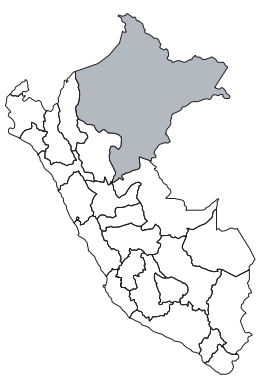
Herbarios: MO; AMAZ!

Registro departamental: LO.

SINANPE: RNAM

Publicación: Novon 2(4): 335, f. 2. 1992. Colección tipo: A.H. Gentry et al. 31751

Nombre común: Desconocido.

Regiones Ecológicas: BHA; $140 \mathrm{~m}$.

Herbarios peruanos: AMAZ (isotipo).

Observaciones: Árbol conocido, al parecer, sólo de una localidad, en la cuenca del Nanay. Esta especie crece en suelos arenosos (Vásquez, 1997). Aun cuando cuenta con poblaciones en un área protegida, la deforestación por impacto urbano podría ser una amenaza.

\section{Zanthoxylum albuquerquei D.R. Simpson}

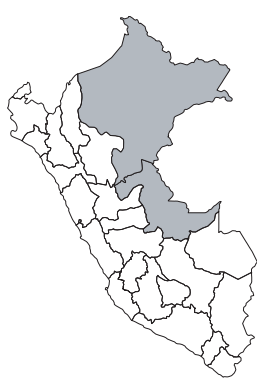

\section{EN, B1ab(iii)}

Publicación: Phytologia 51: 314-315. 1982.

Colección tipo: M. Castillo 28

Herbarios: F; AMAZ!

Nombre común: Desconocido.

Registro departamental: LO, UC.

Regiones Ecológicas: BHA; $130 \mathrm{~m}$.

SINANPE: Sin registro.

Herbarios peruanos: AMAZ (isotipo).

Observaciones: Árbol de valor maderable, conocido de dos localidades en la Amazonía peruana. La localidad tipo está ubicada en la cuenca del Ucayali y aparentemente no ha vuelto a ser recolectada ahí. Tala con fines madereros podría ser una amenaza a sus poblaciones. Aparentemente no ha vuelto a ser recolectada desde 1980. 